\title{
The effect of feed overload at secondary coal separation with product recirculation
}

\author{
Sergiusz Boron ${ }^{1, a}$, Adam Heyduk ${ }^{1}$, Joachim Pielot ${ }^{1}$ \\ ${ }^{1}$ Silesian University of Technology, Department of Electrical Engineering and Control in Mining, 44-100 Gliwice, \\ ul. Akademicka 2, Poland
}

\begin{abstract}
For coal separation with product recirculation, there is a risk of an excessive increase in the amount of feed. Protection against this effect can be achieved by an adequate control of the recirculated material amount. The paper presents a control analysis and economic results of separation in either one or two jigs. The advantage of a slight jig performance oversizing and application of video monitoring in their control systems were justified.
\end{abstract}

\section{Secondary separation with product recirculation}

Secondary separation means repeated separation of intermediate product (aggregates of useful mineral and gangue). This product is usually crushed in order to separate the grains of minerals and gangue [2], but sometimes crushing may not be advisable [13]. There can be also applied recirculation (Fig. 1) of the part of the concentrate (system $1 \mathrm{jig}^{\circ} \mathrm{rC}$ ) or of an intermediate product when using threeproduct jigs (system 2 jig $r C W$ ). Product recirculation is applied to metal ore flotation [16]. Also for the coal flotation it is possible to obtain better beneficiation results by appropriate configuration and recirculation of the flotation products [6]. However, there are very few studies on coal gravity separation with product recirculation $[9,12,15,17,18]$. Improved washing efficiency can be expressed by less erroneous grains in the concentrate and the waste [10].

a)

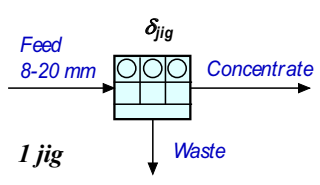

b)

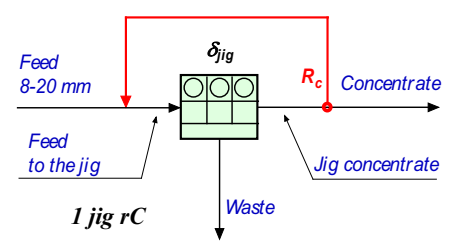

c)

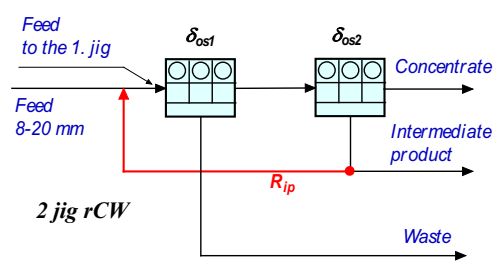

Figure 1. Diagrams of considered technological systems with jigs. Symbol $r C W$ means recirculation of intermediate fractions from the first jig and (at the same time) sinking fractions from the second jig.

All of the following results of simulation predictions have been carried out with the use of array models of jig separation curves [5]. Secondary enrichment is particularly important when coal is

${ }^{a}$ Corresponding author: Sergiusz.Boron@polsl.pl 
resistant to washing. So, the analysis has been limited only to the hardly washable feed, which density-quality characteristics are given in Table 1 [12].

Table 1. Density-quality characteristics of the raw feed stream $(8-20 \mathrm{~mm})$.

\begin{tabular}{|c|c|c|c|c|c|}
\hline $\begin{array}{c}\text { No. of } \\
\text { dens. } \\
\text { fraction }\end{array}$ & $\begin{array}{c}\text { Fraction } \\
\text { density } \\
\mathbf{g} / \mathbf{c m}^{\mathbf{3}}\end{array}$ & $\begin{array}{c}\text { Yield of } \\
\text { fraction } \\
\mathbf{\%}\end{array}$ & $\begin{array}{c}\text { Ash } \\
\text { content } \\
\mathbf{\%}\end{array}$ & $\begin{array}{c}\text { Total sulphur } \\
\text { content } \\
\mathbf{\%}\end{array}$ & $\begin{array}{c}\text { Calorific } \\
\text { value } \\
\mathbf{k J} / \mathbf{k g}\end{array}$ \\
\hline 1 & $<1.30$ & 12.15 & 4.67 & 0.84 & 30680 \\
\hline 2 & $1.30-1.35$ & 17.96 & 7.40 & 0.86 & 29630 \\
\hline 3 & $1.35-1.40$ & 10.95 & 10.99 & 0.97 & 28300 \\
\hline 4 & $1.40-1.50$ & 8.47 & 17.92 & 1.10 & 25750 \\
\hline 5 & $1.50-1.60$ & 7.43 & 26.61 & 1.24 & 22550 \\
\hline 6 & $1.60-1.70$ & 7.02 & 35.81 & 1.25 & 19160 \\
\hline 7 & $1.70-1.80$ & 3.95 & 43.81 & 1.13 & 16220 \\
\hline 8 & $1.80-1.90$ & 4.04 & 51.03 & 1.12 & 13560 \\
\hline 9 & $1.90-2.00$ & 2.57 & 57.08 & 1.39 & 11330 \\
\hline 10 & $>2.00$ & 25.45 & 75.84 & 2.75 & 4420 \\
\hline \multirow{2}{*}{2} & Total & 100.00 & 33.67 & 1.46 & 19960 \\
\cline { 2 - 6 } & & & & & \\
\hline
\end{tabular}

In the 1 jig $r C$ system (Fig. 1 b) ratio $R_{c}$ indicates how much of the concentrate stream from the jig goes back to repeated separation. Similarly, a recirculation factor $R_{i p}$ in the 2 jig $r C W$ system (Fig. 1c) determines what part of the of intermediate product stream returns again to the input.

\section{The effect of feed amount overload}

Repeated separation of the part of the concentrate from the jig (Fig. 1b) means that with an increase in recirculation ratio $R_{c}$ there increases significantly the relative amount of feed to the jig (Fig. 2a). The largest increase takes place at the highest separation density in a jig, because in this case there is a greater participation of the concentrate separated again. When changing raw coal beneficiation or density separation there can occur an uncontrolled increase in the feed amount. A better solution to this problem is to recirculate the intermediate product stream because in this case recirculate mainly erroneous particles (Fig. 2b, results obtained for a constant separation density in the first jig -1.950 $\mathrm{g} / \mathrm{cm}^{3}$ and three separation densities in the second jig: $1.450,1.700$ or $1.950 \mathrm{~g} / \mathrm{cm}^{3}$ ). Also in this case the feed amount may be dangerously increased, but it is possible to tune the control in order to avoid this effect. Feed overload can be avoided when the separation densities in both jigs (or more generally in both separators) do not differ much. For example, if in the first jig separation density is equal to $1.700 \mathrm{~g} / \mathrm{cm}^{3}$, and in a second jeig is equal to $1.950 \mathrm{~g} / \mathrm{cm}^{3}$, then the increase in the feed amount, with the full recirculation of intermediate product $\left(R_{i p}=100 \%\right)$ is less than $39 \%$ and at equal separation densities $\left(1.950 \mathrm{~g} / \mathrm{cm}^{3}\right)$, this increase is $3 \%$.

The dangerous effect of an excessive increase in the feed amount can be controlled using a system of visual analysis of particle size distribution [3], so that the reaction to the excessive increase in the feed amount can done be rapid changes in the recirculation ratio or by the relevant changes in separation density values. 
a)

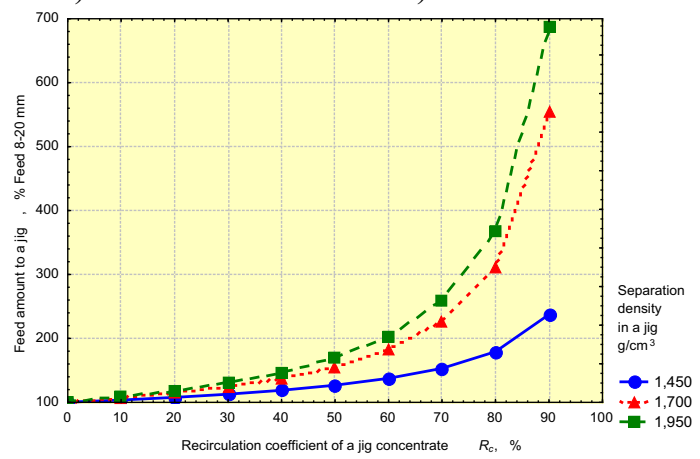

b)

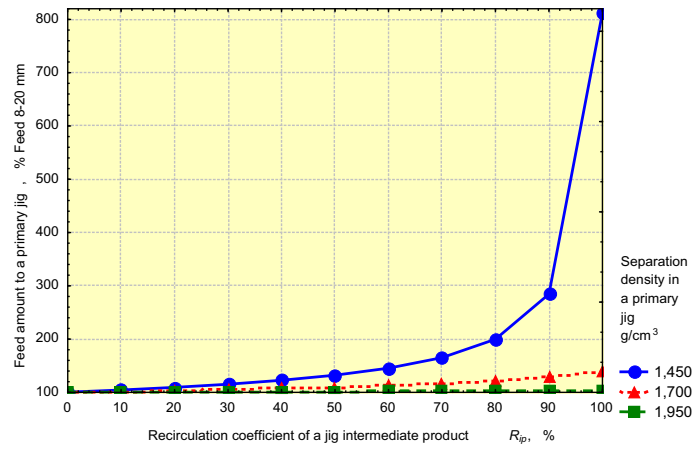

Figure 2. Relative feed flow (quantity) to a jig (in system 1 jig $r C$ - Fig. a) or primary jig (in system 2 jig $r C W-$ Fig. b) at changes of recirculation coefficient of a concentrate from jig $R_{c}$ or intermediate product $R_{i p}$.

In order to assess whether the use of recirculation systems gives better results than in the case of a single jig, there have been calculated maximum production values at various concentrate quality levels in all the systems presented in Fig. 1.

\section{Optimum control with product recirculation}

Algorithm of desired quality production maximization [12] has been used again for optimization calculations. The production value $(P V)$ in a 1 jig $r C$ system (Fig. 1b) is defined by the equation:

$$
P V_{i}\left(\delta_{j i g}, R_{c}\right)=M_{C i}\left(\delta_{j i g}, R_{c}\right) \cdot P_{C i}\left(\delta_{j i g}, R_{c}\right)-M_{W i}\left(\delta_{j i g}, R_{c}\right) \cdot C_{W},
$$

and is an objective function of the maximization algorithm, so there is a need to find its maximum:

$$
\max _{\left(\delta_{j i g}, R_{c}\right) \in R^{n}} P V_{C i}\left(\delta_{j i g}, R_{c}\right)
$$

with a strict limitation of the concentrate ash content value:

$$
A_{C}=A_{C i},
$$

for subsequent values of $A_{C i} 9,12,15$ and $18 \%$

where: $\delta_{j i g}-$ jig separation density, PLN $/ \mathrm{cm}^{3}$

$R_{c}$ - partial recirculation coefficient of the jig concentrate, $\%$

$M_{C}, M_{W}$ - concentrate and waste masses, $\mathrm{Mg}$

$P_{C i}$ - concentrate unit price, dependent on the coal quality, PLN/Mg [8]

$C_{W}$ - the unit cost of waste disposal, PLN/Mg.

Setting the relevant jig concentrate ash content values, the production maximization algorithm finds optimum separation densities in a jig, at different recirculation ratio values. It has been assumed that the density distribution in the jig can be changed in the range of $1.300-1.950 \mathrm{~g} / \mathrm{cm}^{3}$.

In the discussed system with partial jig concentrate recirculation $1 \mathrm{jig} r C$, adjusted jig separation densities increase with increasing $R_{c}$ value (Fig. 3), because the jig feed ash content decreases (as there is an increase in share $n$ of the recirculated concentrate) [7,12]. The production value increases with good concentrate quality with a distinct maximum (Fig. 4). It is assumed that the maximum production value possible to achieve in a single jig without recirculation 1 os (Fig. 1a) is reference value and is regarded as $100 \%$. The problem is a very large increase in the jig feed amount, at high values of $R_{c}$. When $R_{c}$ value does not exceed e.g. $40-50 \%$, then, in accordance with Fig. 2a, the 
increase in jig feed amount is small. Separation in jig, slightly oversized in terms of performance, allows for even a few percent increase in the production value (Fig. 4) in the case of a high quality concentrate, without installing additional processing machines. Larger jig also makes possible to respond flexibly to increased raw coal amount because at increasing raw coal stream it is simple to reduce the ratio of the recycled product.

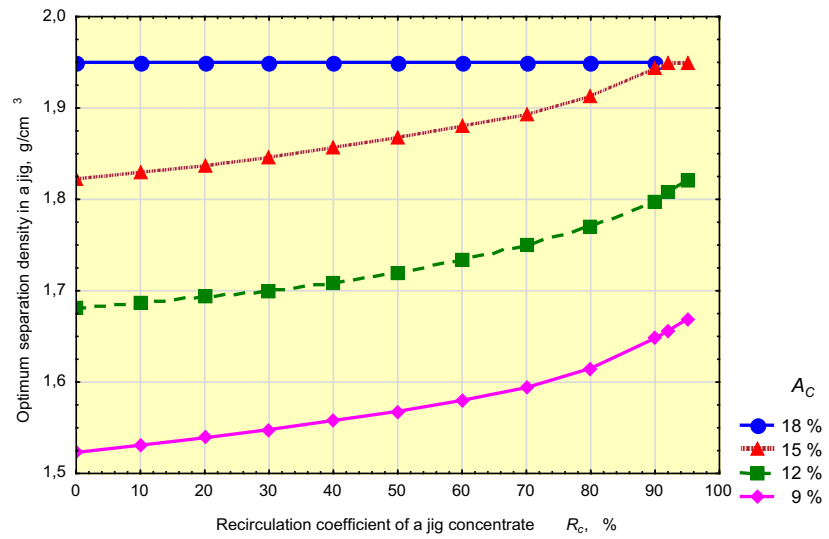

Figure 3. Optimum separation densities in a jig at changes of recirculation coefficient of concentrate from jig $R_{c}$ in 1 jig $r C$ system.

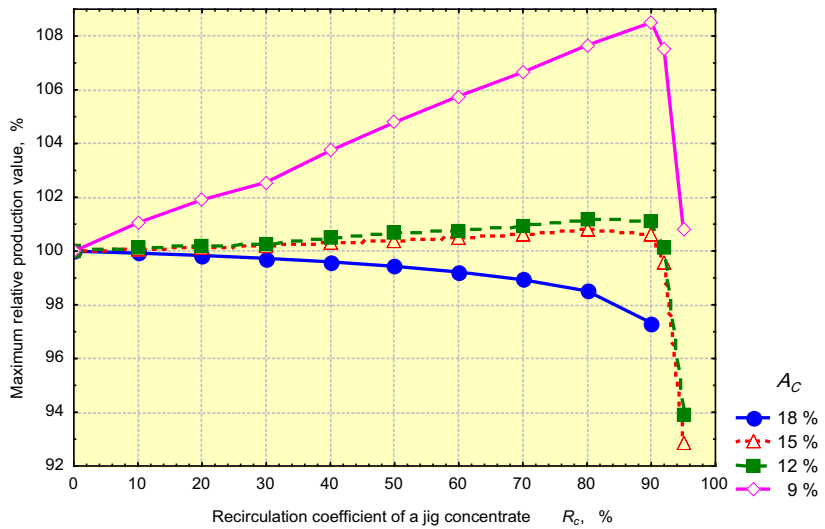

Figure 4. Maximum relative production value from a jig at changes of recirculation coefficient of concentrate from jig $R_{c}$ in 1 jig $r C$ system.

Similarly as in Fig. 1b, either a portion or all of the intermediate product can be re-entered to the input of the three-product separator or to the input of the system of two two-product separators. This layout is illustrated in Fig. 1c. A recirculation ratio defines what portion of the intermediate product flow returns back to the input, and is mixed with the raw input (feed stream of 8-20 mm).

The concentrate production value has been established as an objective function for the maximization algorithm. For a system with a single jig without recirculation 1 jig (Fig. 1a):

$$
P V_{i}\left(\delta_{j i g}\right)=M_{C i}\left(\delta_{j i g}\right) \cdot P_{C i}\left(\delta_{j i g}\right) \text {. }
$$

In the 2 jig $r C W$ system (Fig. 1c) with intermediate product recirculation it is possible to obtain a desired concentrate quality in various combinations of control signals. It has been assumed that all the intermediate product recirculates (which is acceptable at small differences between separation 
densities in both jigs), and thus the recirculation ratio assumes the value of $R_{i p}=100 \%$. The production value is determined by the equation:

$$
P V_{i}\left(\delta_{j i g 1}, \delta_{j i g 2}\right)=M_{C i}\left(\delta_{j i g 1}, \delta_{j i g 2}\right) \cdot P_{C i}\left(\delta_{j i g 1}, \delta_{j i g 2}\right) .
$$

There are maximized functions (4) and (5) (in the whole range of possible to obtain values of the concentrate ash content) with en equivalence constraint of subsequently asked $1 \%$ increments of the concentrate ash content:

$$
A_{C}=A_{C i} .
$$

Entering to the production value maximization algorithm consecutive values of the concentrate ash content $A_{K i}$ there can be obtained optimum separation densities for jigs (within a predetermined range of $1.300-2.200 \mathrm{~g} / \mathrm{cm}^{3}$ ). These calculated optimum separation densities are shown in Fig. 5.

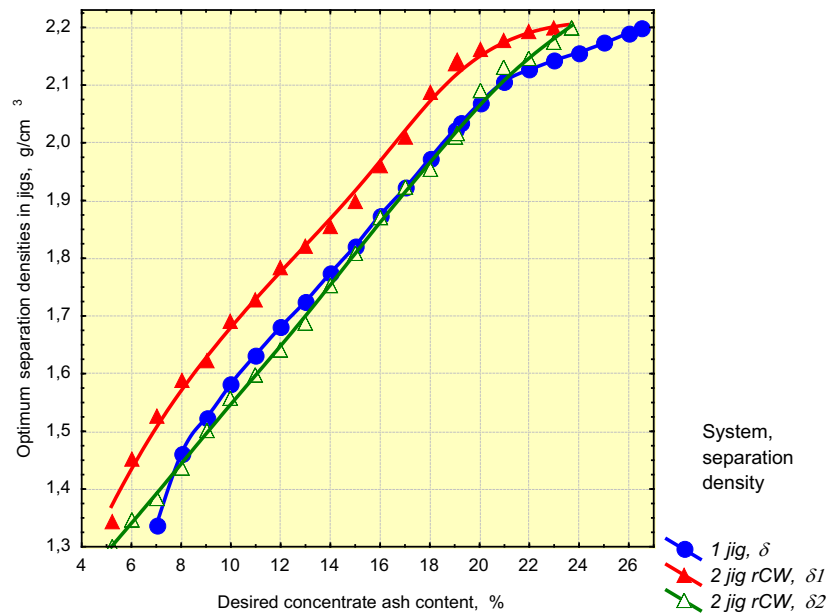

Figure 5. Optimum separation densities in one jig (1 jig) and in system (2 jig $r \mathrm{CW})$ with recirculation of an intermediate product for $R_{i p}=100 \%$.

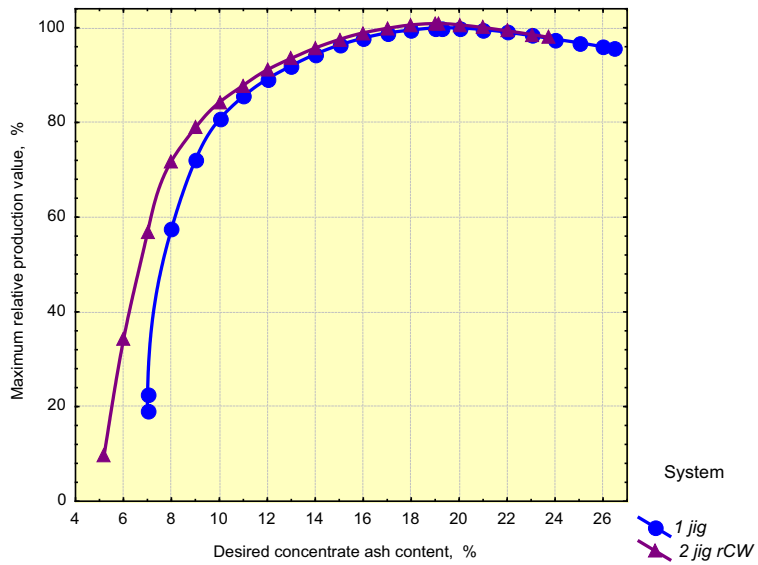

Figure 6. Maximum relative production value of a concentrate in one jig (1 jig) and in 2 jig $r C W$ system with recirculation of an intermediate product for $R_{i p}=100 \%$. 
Changes in the maximum production value of the desired quality are illustrated in Fig. 6. In each case in a system with recirculation there can be achieved a higher production value than in the case of a single-jig layout. This is particularly important for small desired values of the concentrate ash contents. Furthermore, as shown elsewhere [4], the use of product recirculation at the desired high quality of the concentrate is economically profitable. Figure 7 shows the relative amounts of feed input to the jigs.

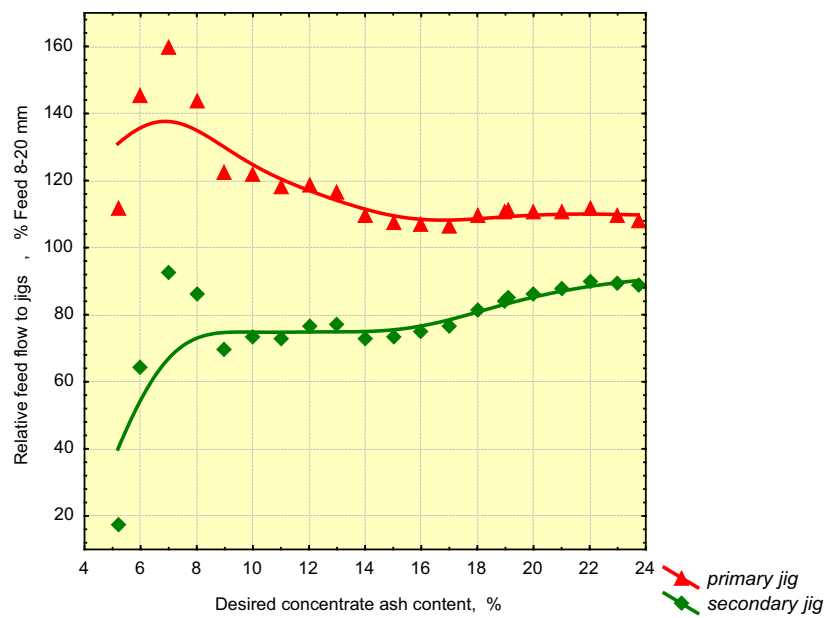

Figure 7. Relative feed flow to jigs in 2 jig $r C W$ system with recirculation of an intermediate product for $R_{i p}=100 \%$.

\section{Summary}

In the case of the concentrate recirculation in a roughly exponential manner increases the amount of feed to the separators. This unfavorable effect is entirely possible to be omitted in the case of the intermediate product recirculation when the separation densities distribution in both separators do not differ significantly from each other.

A dangerous effect of an excessive feed amount increase can be controlled using a system of machine vision analysis of particle size distribution [3]. Therefore, a reaction to this excessive feed amount increase may be performed by rapid changes in a recirculation ratio or relevant changes in density distribution.

The use of product recirculation - in some cases - enables an increase in the production value. For coal washing in a single jig, the increase in output value is obtained by using the secondary washing of the small part of the concentrate stream. At low values of the desired concentrate ash content (Fig. 4). The increase in production value may even be in a several percent range.

Partial concentrate recirculation is the easiest (practically without investments) way to increase the production value of good quality concentrate. However this is connected with a considerable increase in the feed amount. It seems that the useful value of the concentrate recirculation ratio is restricted to about $40-50 \%$ (Fig. 2a).

In systems with the intermediate product recirculation there can be always obtained higher production value than the output value of the single-separator system. This is particularly important at low desired concentrate ash contents values.

The use of product recirculation systems requires a slightly oversized jigs, but it is more cost effective than installing additional processing machines. Improvement in the operational functioning of the intermediate product recirculation circuit can be obtained by the use of video monitoring 
systems allowing to react flexibly to the changes in feed amount by dynamic changes in recirculation coefficient values.

\section{References}

1. W. Blaschke, Przeróbka węgla kamiennego - wzbogacanie grawitacyjne (Wydawnictwo IGSMiE PAN, Kraków, 2009)

2. J. Blaschke (i in.), IM, Kraków, 4 (17) (2006)

3. S. Boron, A. Heyduk, J. Pielot, in Proceedings of XIX Mineral Engineering Conference 2014, (Istebna, 2014)

4. S. Boron, J. Pielot, A. Wojaczek, Miner. Resou. Manag., 30(2), 67 (2014)

5. F. Goodman, J. McCreery, Coal Prep. Comp. Model, 1 (1980)

6. K. Kalinowski, Network Integrators Associates (Parkland, Florida, 2007)

7. K. Kalinowski, J. Pielot, Mechanizacja i Automatyzacja Górnictwa, 12(431), 41 (2006)

8. U. Lorenz, W. Blaschke, Z. Grudziński, Monography (Wydawnictwo IGSMiE PAN, Kraków, 112, 2002)

9. G.H.Luttrell, Coal Prep. 24, 35 (2004)

10. J. Martyniak, Wiadomości Górnicze, 5, 235 (1996)

11. J. Pielot, Mechanizacja i Automatyzacja Górnictwa, 12 (443), 23 (2007)

12. J. Pielot, Monograph (Wydawnictwo Politechniki Śląskiej, Gliwice, 306, 2011)

13. J. Pielot, in Proceedings of Mineral Engineering Conference MEC 2015 (Szczawnica, 20, 2015)

14. J. Pielot, in Proceedings of Mineral Engineering Conference MEC 2015 (Szczawnica, 24, 2015)

15. A.I.A. Salama, M.W. Mikhail, in Proceedings of XII International Coal Preparation Congress, (Krakow, 4, 43 1994)

16. K. Trybalski, Kontrola, modelowanie i optymalizacja procesów technologicznych przeróbki rud, (Wydawnictwo AGH, Kraków, 2013)

17. R.B. Venkoba, P.C. Kapur, Int.l J. Miner. Process. 89, 23 (2008)

18. H. Yagun, L. Shan, L. Maixi, K. Yali, L. Huaiyu, Coal Prep., 22, 93 (2002) 